\title{
Pleural mesothelioma in Sweden: an analysis of the incidence according to the use of asbestos
}

\author{
Bengt Järvholm, Anders Englund, Maria Albin
}

\begin{abstract}
Objective-To investigate if the preventive measures taken to reduce the occupational exposure to asbestos have resulted in a decreased incidence of pleural mesothelioma in Sweden.

Methods-The incidence of pleural mesothelioma between 1958 and 1995 for birth cohorts born between 1885 and 1964 was investigated. The cases of pleural mesothelioma were identified through the Swedish Cancer Register.

Results-In 1995, around 80 cases of pleural mesothelioma could be attributed to occupational exposure to asbestos. There is an increasing incidence in more recent birth cohorts in men. The incidence was considerably higher in the male cohort born between 1935 and 1944 than in men born earlier.

Conclusions-The annual incidence of pleural mesothelioma attributable to occupational exposure to asbestos is today larger than all fatal occupational accidents in Sweden. The first asbestos regulation was adopted in 1964 and in the mid 1970s imports of raw asbestos decreased drastically. Yet there is no obvious indication that the preventive measures have decreased the risk of pleural mesothelioma. The long latency indicates that the effects of preventive measures in the 1970 s could first be evaluated around 2005. (Occup Environ Med 1999;56:110-113)
\end{abstract}

Keywords: attributable risk; epidemiology; occupation

Department of

Medical and Social

Affairs, National

Board of Occupational

Safety and Health, S-171 84 Solna,

Sweden

A Englund

Department of Occupational and Environmental Medicine, Lund University, S-221 85 Lund, Sweden

M Albin

Correspondence to: Professor Bengt Järvholm, Department of Occupational and Environmental Medicine, Umeå University, S-901 85 Umeå, Sweden. Telephone 004690785 2241; fax 0046907852456 ; email bengt.jarvholm@ envmed.umu.se

Accepted 17 September 1998 cement products, insulation in production of brake linings, and for insulation in industry. An increased risk of mesothelioma has been found in the Swedish asbestos cement industry, ${ }^{4}$ in the Swedish shipyard industry, ${ }^{5}$ in maintenance workers in the Swedish pulp and paper industry, ${ }^{6}$ and in Swedish insulation workers and other construction workers. ${ }^{78}$ There are no official statistics of which type of asbestos was used in Sweden, but a common estimate is that at least $90 \%$ was chrysotile. ${ }^{9}$ Studies of the Swedish shipyard and asbestos cement industries have shown that the main fibre type was chrysotile. ${ }^{510}$

Analyses of cancer mortality in the United Kingdom, ${ }^{11}$ and Finland, ${ }^{12}$ have indicated that the increase in the incidence of pleural mesothelioma has not yet been converted into a decrease as a result of the preventive measures taken. Furthermore, most cases are not found in asbestos mining or manufacturing of asbestos products, but predominantly in construction workers. A trend analysis of mortality in the United States indicates a decreasing incidence in recent birth cohorts which was interpreted as a result of a decreasing use and exposure to asbestos in United States during recent years. ${ }^{13}$ Due to the long latency time, the excess risk of pleural mesothelioma caused by asbestos exposure in the early occupational cohorts of workers could be expected to remain for several years. The objective of this study was to investigate if the preventive measures in Sweden in the mid-1970s to reduce the occupational exposure have resulted in a decreased incidence of pleural mesothelioma.

\section{Materials and methods}

The analysis is based on the national Swedish Cancer Register. It was established in 1958 and there is a legal requirement that all cases of cancer should be reported to the registry. Most cases are reported both by a clinician and a pathologist. The register contains site and histological type. We only used cases who had both the site for pleural tumours (international classification of diseases 7 th edition (ICD-7) code 162.2) and the histological diagnosis of mesothelioma (code 776) in the analysis. The incidence was calculated stratifying for sex, age, and birth cohort between 1958 and 1995 . To adjust for different size of the birth cohorts, incidences were calculated stratifying for sex, birth cohort, and age by dividing the number of cases by the number of person-years in the strata. The number of person-years in each strata was calculated from national statistics. ${ }^{14}$ Because the precision in diagnostics may decrease in higher age groups, only the incidence below the age of 79 years was included.
USE AND REGULATION OF ASBESTOS IN SWEDEN The awareness of an increased risk of lung cancer and mesothelioma due to asbestos exposure has resulted in different measures to reduce the exposure. The first regulation of the use of asbestos was passed in 1964 in Sweden and was mainly aimed at reducing the risk of lung fibrosis, asbestosis. There was no limit value but the regulations recommended that asbestos should be replaced wherever possible. The workers should be informed about the risk of asbestosis. Measures to reduce the dustsuch as wetting - were recommended. Respira- 


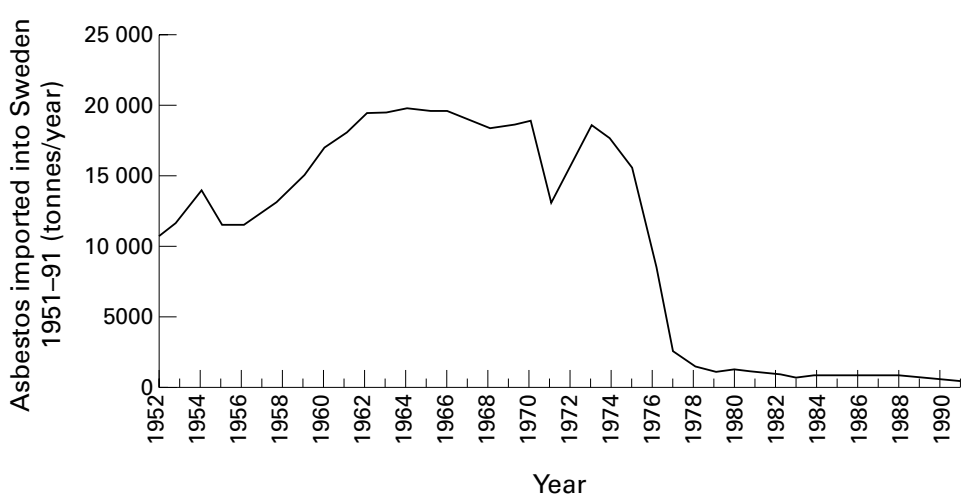

Figure 1 Imports of raw asbestos to Sweden 1952-91.

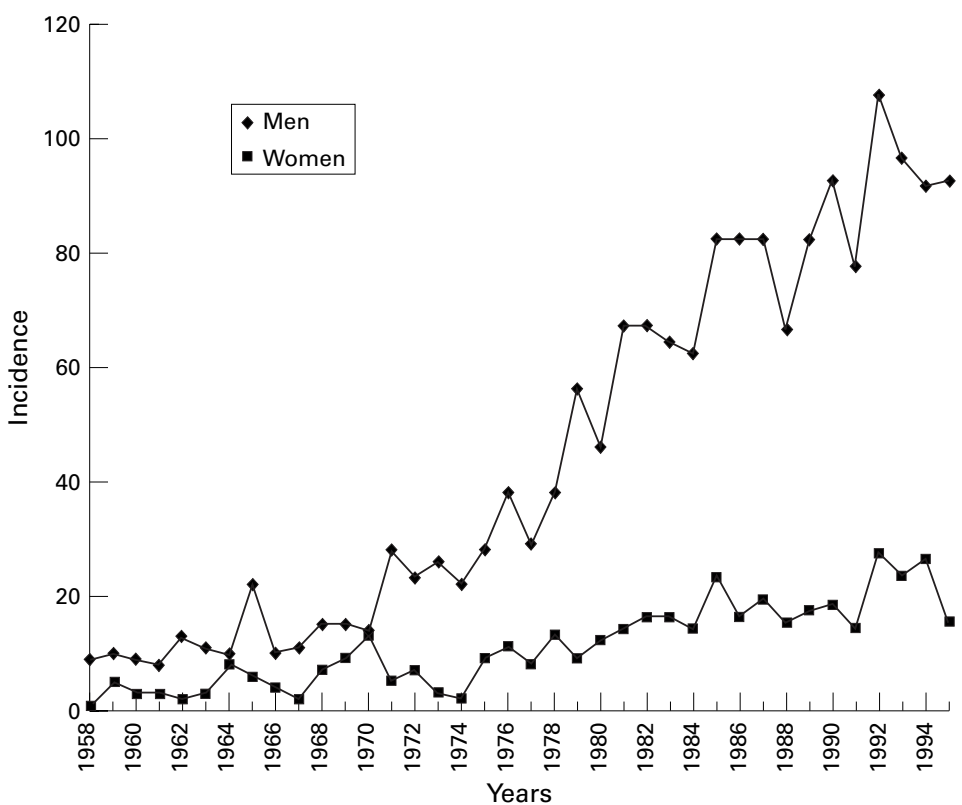

Figure 2 Annual incidence of pleural mesothelioma in Sweden 1958-95.

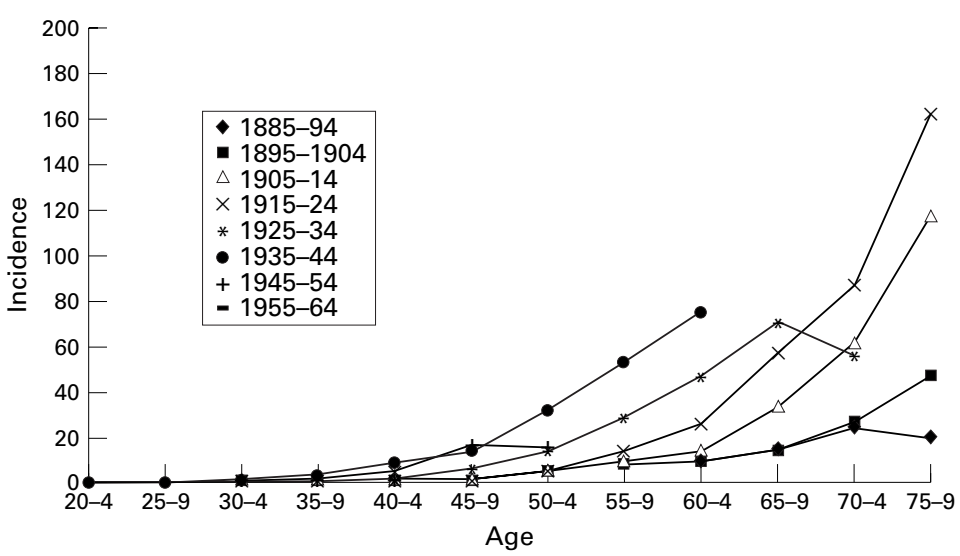

Figure 3 Incidences (Imillion person-years) of pleural mesothelioma according to age for men 1958-95 in cohorts born 1885-1964.

tors should be used if the work was dusty. There was a strong, but not mandatory, recommendation to carry out medical examinations of workers exposed to asbestos. For a single company, the National Board of Occupational Safety and Health (NBOSH) could direct medical examinations. It is not known how often $\mathrm{NBOSH}$ prescribed such examinations.
The first permissible exposure concentration of $2 \mathrm{fibres} / \mathrm{ml}(\mathrm{f} / \mathrm{ml})$ was introduced in 1975. In 1976 this was reduced to $1 \mathrm{f} / \mathrm{ml}$ and in 1985 reduced to $0.5 \mathrm{f} / \mathrm{ml}$. Since 1988 the permissible limit for asbestos is $0.2 \mathrm{f} / \mathrm{ml}$.

In the early 1970 s the increased risk of cancer in workers exposed to asbestos was brought up for discussion at the Swedish Parliament. Furthermore, in the mid-1970s the risks were repeatedly dealt with by the media. There was a general awareness of the hazards in the construction industry-workers and contractors alike. The revised issue of directions and notices on work with asbestos was adopted in 1975 and contained a strong recommendation to replace asbestos. The use of crocidolite was prohibited in 1975 and followed in 1976 by the prohibition of the installation of asbestos cement products. These regulations related only to new projects. Consequently, the import of raw asbestos decreased drastically in the mid 1970s (fig 1). This implied that the number of Swedish workers exposed to asbestos decreased.

In 1982 , there was a general prohibition on the use, machining, and processing of the other types of asbestos as well as crocidolite and all materials containing asbestos. There were some exceptions - such as brake linings, other friction materials, and gaskets-if no acceptable replacements were available. Companies were required to have a permit for use of asbestos and material containing asbestos.

In 1986 a regulation was adopted requiring special training for workers who demolish asbestos and material containing asbestos.

In 1986, the Government ordinance prohibiting asbestos from friction linings in vehicles (SFS 1986:683, amended in SFS 1988:1075) specifically prohibited friction materials containing asbestos in vehicles manufactured after 1989.

\section{Results}

The annual incidence of pleural mesothelioma has increased considerably between the 1960 s and 1980s, especially among men (fig 2). In 1995 there were 92 cases of pleural mesothelioma in men and 15 cases in women. There is an increasing incidence in recent birth cohorts in men, but no such tendency is found in women (figs 2 and 3). Of special interest are the youngest birth cohorts (table). Below the age of 35 the incidence is very low and not suitable for trend analysis. Birth cohorts born until 1944 include all ages up to 49 years of age and the highest number of cases occurred in the 1940-4 cohort. The crude incidences for ages 20-49 years in the cohorts 1930-4, 1935-9, and 1940-4 is highest in the latest cohort (0.2, 0.6 , and 0.7 cases $/ 1000$ person-years). An analysis of men 35-9 years of age indicated a decreased incidence in the birth cohort born 1950-4 (one case) and a peak in the birth cohort born 1940-4 (seven cases; p<0.01, binomial distribution). The corresponding number in women is zero to one case. 
Incidence of pleural mesothelioma in birth cohorts born between 1930 and 1964, men

\begin{tabular}{llllllll}
\hline Age & $1930-4$ & $1935-9$ & $1940-4$ & $1945-9$ & $1950-4$ & $1955-9$ & $1960-4$ \\
\hline $20-4$ & & & 1 & 0 & 1 & 0 & 1 \\
$25-9$ & & 0 & 2 & 1 & 2 & 0 & 2 \\
$30-4$ & 1 & 0 & 2 & 1 & 1 & 0 & \\
$35-9$ & 2 & 3 & 7 & 4 & 1 & & \\
$40-4$ & 0 & 10 & 12 & 9 & & & \\
$45-9$ & 6 & 16 & 18 & & & & \\
$\mathrm{n}^{\star}$ & 45716 & 48969 & 61946 & 67175 & 60863 & 58085 & 63364 \\
\hline
\end{tabular}

^Number of people in birth cohort at 30 years of age.

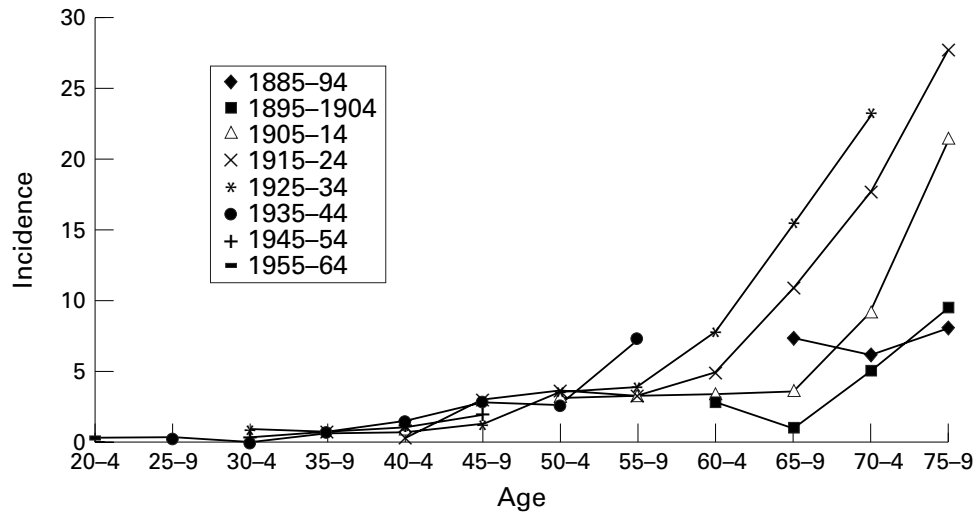

Figure 4 Incidences (/million person-years) of pleural mesothelioma according to age for women 1958-95 in cohorts born 1885-1964.

\section{Discussion}

This study shows that the risk of pleural mesothelioma is increasing in more recent birth cohorts, mainly among men. There is also a cohort trend among women, but at a much lower level (fig 4). The sex differences strongly support an occupational origin to the increased risk, as mainly men were occupationally exposed to asbestos in Sweden. ${ }^{15}$ Shipyards, insulation, and construction industries were mainly workplaces for men. The increasing incidence in recent birth cohorts until and including the birth cohort 1935-44, is alarming and indicates that many Swedes in the future will die of pleural mesothelioma caused by occupational exposure to asbestos.

Changes of diagnostic procedures may have been important in the increased trend, at least during the 1960s. As the increasing incidence is mainly limited to men, and not to women, this indicates that changes in diagnostic procedures are not a major cause of the increased incidence in men. An increased awareness of asbestos exposure in men, and thus a bias of diagnosis, also seems improbable. The diagnosis is usually made by a pathologist unaware of the exposure of the case. Furthermore, an investigation of pleural mesothelioma in Sweden indicated that in most of the cases in the 1980 s, the medical records did not contain any information about possible exposure to asbestos. ${ }^{16}$ Moreover, in a cohort of construction workers examined in the early 1970 s few of those who later developed mesothelioma of the pleura were aware of their exposure to asbestos, although their types of job certainly made such exposure most likely. ${ }^{8}$ Accordingly they could never have told their physician about the exposure.

There is no known difference between men and women in the natural risk of pleural mesothelioma. ${ }^{17}$ Furthermore, some of the cases among women may be due to occupational exposure to asbestos or indirect exposure to asbestos-for example, from working cloths. ${ }^{18}$ Thus, of the 107 cases of pleural mesothelioma in 1995, 70-80 cases were caused by occupational exposure to asbestos if we just consider the difference between men and women $(92-15=77)$. In Sweden in the same year there were 61 fatal occupational accidents and consequently, as pleural mesothelioma is basically an incurable disease, one single asbestos related disease alone in the mid-1990s caused more deaths than all occupational accidents together. There are also cases of fatal lung cancer that could be attributable to exposure to asbestos; two Swedish population based studies indicate a population attributable risk between $16 \%$ and $19 \%$ in men. ${ }^{15}$ No undisputed safe limit of exposure to asbestos has been shown. To show that a national regulation is efficient to prevent a disease is different from showing that a disease is not increased in a group exposed to a certain level of exposure. A regulation should also be easily understood - that is, even in small firms with a low level of risk there should be awareness. Even if a safe use of asbestos could be implemented in the production industry, the risk may persist among some of the users of asbestos products. Our data are insufficient to show if the Swedish regulations in the 1970s will prevent the occurrence of occupational mesothelioma as the follow up is too short. We think that because of these uncertainties and the severe impact of previous use of asbestos in Sweden measures to decrease the exposure to asbestos should have a high priority.

The risk of mesothelioma associated with asbestos is dependent on dose and time since the onset of exposure (latency); a common model indicates linear dependence of dose and a power function of latency. ${ }^{20}$ The first regulation of asbestos was introduced in the early 1960s and subjects who started their occupational career in the 1960s should have been exposed to lower doses on average, than those who started earlier. On the other hand, by the 1960 s asbestos was being used more extensively so the number of people exposed to asbestos may have increased. Subjects born during the 1940s started their occupational career during the 1960 s but there is no indication that they have a decreased risk of pleural mesothelioma. The regulations during the 1960s may therefore have been insufficient to protect the workers. More stringent regulations of asbestos were introduced in the mid-1970s, which led to the sharp decrease in its use (fig 1). People who have only worked under such conditions were born from 1955 onwards. They have not yet reached a sufficient latency time for possible mesotheliomas to have developed so the number of cases are few. However, the first indication is that they may have a decreased risk compared with earlier birth cohorts (table). A more certain conclusion can probably not be drawn for another 10 years. Thus, the preventive measures of the mid- 
1970s can probably not be evaluated with reasonable precision until around 2005, 30 years later.

The present situation in Sweden, that mortality from mesothelioma due to earlier use of asbestos is of a similar size to the total number of fatal occupational accidents, is caused by a situation in which at least $90 \%$ of the asbestos used was chrysotile. However, we have no information about the type of exposure to asbestos among the cases of mesothelioma-whether they had an exposure to crocidolite or amosite. There is some pressure from the asbestos industry world wide to change the asbestos regulations to allow the use of chrysotile. To evaluate such an experiment would take at least another 30 years. Even if the major cause of mesothelioma in Sweden was from types of asbestos other than chrysotile, it is difficult to see how the benefits from an increased use of asbestos in Sweden could outweigh the uncertainty of the risks. A similar prudent approach would also be appropriate in other European countries including European Union members where national population based data on health risks are not as accessible as they are in the Nordic countries and the United Kingdom.

1 Johansson L. Asbestos related disease: histopathological, immunohistochemical, and ultrastructural examinations [thesis] Lund, Sweden: Lund University, 1992

2 Parion JC, Orlowdki E, Iwatsubo Y, et al. Pleural mesothelioma and exposure to asbestos: evaluation from work histories and analysis of asbestos bodies in bronchoalveolar lavage fluid or lung tissue in 131 patients. Occup Environ Med 1994;51:244-9.

3 Tuomi T, Huuskonen M, Tammilehto L, et al. Occupational exposure to asbestos as evaluated from work histories and analysis of lung tissues from patients with mesothelioma. arf Ind Med 1991;48:48-52.

4 Albin M, Johansson L, Pooley FD, et al. Mineral fibres, fibrosis, and asbestos bodies in lung tissue from deceased fibrosis, and asbestos bodies in lung tissue from deceased
asbestos cement workers. Br f Ind Med 1990;47:767-74.
5 Sandén Ĺ, Järvholm B, Larsson $\mathrm{S}$, et al. The risk of lung cancer and mesothelioma after cessation of asbestos exposure: a prospective cohort study of shipyard workers Eur Respir f 1992;5:281-5.

6 Järvholm B, Malker H, Malker B, et al. Pleural mesotheliomas and asbestos exposure in the pulp and paper industries: a new risk group identified by linkage of official registers. Am f Ind Med 1988;13:561-7.

7 Sandén L, Järvholm B, Näslund PE. Mortality and morbidity of Swedish insulation workers. Scand $\mathcal{F}$ Work Environ Health 1984;10:207.

8 Engholm G, Englund A, Fletcher AC, et al. Respiratory cancer incidence in Swedish construction workers exposed to man-made mineral fibres and asbestos. Ann Occup Hyg 1987;31:663-75.

9 Asbestkommissionen. Handlingsprogram mot asbest (Actions programme against asbestos). Stockholm: Ministry of Labour, 1985:16. (DsA 1985:5, in Swedish.)

10 Albin M, Jakobsson K, Attewell R, et al. Mortality and cancer morbidity in cohorts of asbestos cement workers and referents. Br ₹ Ind Med 1990;47:602-10.

11 Peto J, Hodgson Jt, Matthews Fe, et al. Continuing increase in mesothelioma mortality in Britain. Lancet 1995;345: 535-9.

12 Karjalainen A, Pukkala E, Mattson K, et al. Trends in mesothelioma incidence and occupational mesotheliomas in Finland in 1960-95. Scand F Work Environ Health 1997;23: 266-70.

13 Price B. An analysis of current trends in United States meothelioma incidence. Am f Epidemiol 1997;145:211-8.

14 Statistics Sweden. Cohort mortality in Sweden. Demografiska rapporter 1997:2. Stockholm: Statistics Sweden, 1997

15 Järvholm B, Larsson S, Hagberg S, et al. Quantitative importance of asbestosis as a cause of lung cancer in a Swedish industrial city: a case referent study. Eur Respir $\mathcal{F}$ 1993;6:1271-5.

16 Andersson E, Torén K. Pleural mesotheliomas are underreported as occupational cancer in Sweden. Am f Ind Med $1995 ; 27: 577-80$

17 Peto J, Henderson BE, Pike MC. Trends in mesothelioma incidence in the United States and the forecast epidemic due to asbestos exposure during World War II. In: Peto R, Schneiderman M, eds. Occupational Cancer 1951-69. Cold Spring Harbor, NY: Cold Spring Harbor Laboratory, 1981. (Banbury Report 9.)

18 Vianna NJ, Polan AK. Non-occupational exposure to asbestos and malignant mesothelioma in females. Lancet 1978; 1061-3.

19 Damber LA, Larsson LG. Occupation and male lung cancer: a case-control study in northern Sweden. $\mathrm{Br} f$ Ind Med 1987;44:446-53.

20 Hughes JM, Weill H. Asbestos exposure: quantitative assessment of risk. Am Rev Respir Dis 1986;133:5-13.

\section{Global theme issue on "The impact of new technologies in medicine": invitation to submit papers}

Many international journals, including Occupational and Environmental Medicine, have agreed to participate in another global theme issue, this time on "The impact of new technologies in medicine", in November 1999. In the field of occupational and environmental medicine, new technologies are relevant to diagnostic and treatment methods. They may also provide ways to reduce hazards in the workplace or general environment. Or they may themselves pose new hazards. We are commissioning articles to cover aspects relevant to occupational and environmental medicine and we are also inviting submission of articles on this theme.

If you would like to submit an article for this global theme issue, please send it to the editorial office as soon as possible and before 15 March 1999. All submitted articles should follow the usual guidelines to authors and will be subject to peer review in the normal way. 